DELLA-FLORA, R.P., DIONELLO, N.J.L. e GERMANO, J.M. Utilização de mananoligossacarídeos como alternativa aos antibióticos na avicultura. PUBVET, Londrina, V. 6, N. 36, Ed. 223, Art. $1480,2012$.

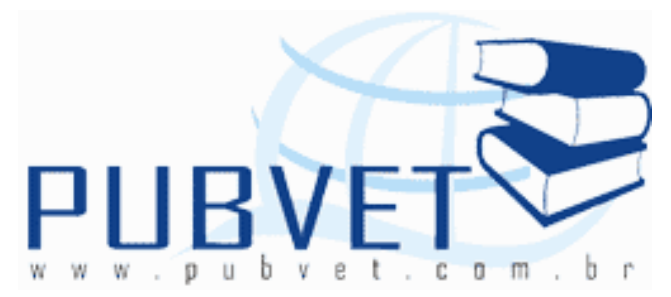

PUBVET, Publicações em Medicina Veterinária e Zootecnia.

\title{
Utilização de mananoligossacarídeos como alternativa aos antibióticos na avicultura
}

Raquel Pillon Della-Flora ${ }^{1}$, Nelson José Laurino Dionello², Jerusa Martins Germano $^{3}$

1 Mestranda em Zootecnia/Bolsista do CnPq. Departamento de Zootecnia. FAEM/UFPel. Pelotas, RS. Brasil.

${ }^{2}$ Prof.Dr. e Bolsista de produtividade do CNPq. Departamento de Zootecnia. FAEM/UFPel.

${ }^{3}$ Aluna do curso de Zootecnia. FAEM/UFPel.

\section{Resumo}

A crescente restrição ao uso de drogas veterinárias como promotores de crescimento na nutrição animal fez com que surgisse uma nova geração de produtos para auxiliar no equilíbrio benéfico da microbiota do trato gastrintestinal (TGI), entre eles, mananoligossacarídeos. Provavelmente um dos papeis mais importantes dos mananoligossacarídeos está na sua capacidade de modificar a morfologia e a estrutura da parede intestinal. Trata-se de um efeito na ecologia microbiana gastrointestinal, com isso os mananoligossacarídeos podem melhorar a eficiência do crescimento através de mecanismos que alteram a estrutura e a atividade funcional dos tecidos. Possivelmente este seja um novo papel dos 
DELLA-FLORA, R.P., DIONELLO, N.J.L. e GERMANO, J.M. Utilização de mananoligossacarídeos como alternativa aos antibióticos na avicultura. PUBVET, Londrina, V. 6, N. 36, Ed. 223, Art. 1480, 2012.

carboidratos funcionais que venha a contribuir para a melhora no desempenho dos mesmos.

Palavras-chave: aves, promotores de crescimento, trato gastrintestinal.

\title{
MOS use as an alternative to antibiotics in poultry
}

\begin{abstract}
The increasing restriction on the use of veterinary drugs as growth promoters in animal nutrition made that appear a new generation of products to assist in the balance of beneficial microflora in the gastrointestinal tract (GIT), including, MOS. Probably one of the most important roles of the MOS lies in its ability to modify the morphology and structure of the intestinal wall. This is an effect on the gastrointestinal microbial ecology. Thus, the MOS can improve the efficiency of growth through mechanisms that alter the structure and functional activity of the tissues. Possibly, this is a new functional role of carbohydrates that will contribute to the improvement in their performance.
\end{abstract}

Keywords: poultry, growth promoters, gastrointestinal tract.

\section{INTRODUÇÃO}

O mercado consumidor esta cada vez mais exigente e existe uma demanda crescente por alimentos mais saudáveis, sem resíduos de antibióticos e agrotóxicos. Algumas substâncias imunoestimulantes vêm sendo utilizadas como alternativa aos antibióticos promotores de crescimento, entre elas determinados prebióticos.

Logo após o nascimento, as superfícies e mucosas dos animais, que, em condições fetais, são estéreis, rapidamente sofrem colonização por diversos microrganismos. Destes, alguns são úteis e outros nocivos. A microbiota útil auxilia na digestão e absorção de nutrientes, produz vitaminas que serão 
DELLA-FLORA, R.P., DIONELLO, N.J.L. e GERMANO, J.M. Utilização de mananoligossacarídeos como alternativa aos antibióticos na avicultura. PUBVET, Londrina, V. 6, N. 36, Ed. 223, Art. 1480, 2012.

utilizadas pelo hospedeiro e diminui, por exclusão competitiva, a proliferação de agentes patogênicos (ROY \& GIBSON, 1999). A nociva pode causar inflamações na mucosa intestinal, gerar metabólitos tóxicos e propiciar o aparecimento de enfermidades. Em condições normais, estas populações encontram se em equilíbrio. No entanto, em condições de estresse (mudança da dieta, alterações climáticas, densidade elevada, ventilação deficiente ou qualquer outra situação desfavorável) as populações úteis diminuem e as nocivas se proliferam, o que se reflete negativamente sobre a saúde e o desempenho animal (MATHEW et al., 1993).

A integridade intestinal das aves tem um impacto direto na eficiência de sua produção, sendo necessária a adoção de medidas visando aumentar a longevidade dos enterócitos, pois a ave gasta cerca de $20 \%$ da energia bruta consumida para manutenção do epitélio intestinal, o que significa um elevado custo energético. Assim, quando ocorrem lesões nesse tecido, além da redução do volume de substrato digerido e absorvido, há ainda uma maior demanda energética para a renovação celular. A energia que poderia estar sendo utilizada para a produção é direcionada para o turnover celular, resultando em um menor ganho de peso e em uma alta conversão alimentar (FRANCO, 2010). Dessa forma, a rentabilidade da atividade avícola é diretamente afetada quando a integridade intestinal está prejudicada.

Para manter o equilíbrio benéfico da microbiota do TGI mesmo em condições de estresse, os principais produtos usados nas últimas cinco décadas foram os antibióticos; esses antibióticos são usados como aditivo alimentar na dieta de frangos, atuando como agentes promotores de crescimento, pois, segundo MATEOS et al. (2004), promovem melhora do ganho de peso e da eficiência alimentar de $1 \%$ a $5 \%$. Outro produto são os quimioterápicos que, em doses subterapêuticas, atuam como promotores de crescimento, diminuindo os 
DELLA-FLORA, R.P., DIONELLO, N.J.L. e GERMANO, J.M. Utilização de mananoligossacarídeos como alternativa aos antibióticos na avicultura. PUBVET, Londrina, V. 6, N. 36, Ed. 223, Art. 1480, 2012.

índices de mortalidade e aumentando a eficiência produtiva e reprodutiva (SALYERS, 1999).

O uso de antibióticos como aditivos promotores de crescimento na avicultura tem sido, bastante questionado atualmente (MACHADO et al., 2007). Desde a segunda metade do século passado, os antibióticos passaram a ser vistos como fator de risco à saúde humana (PELICANO et al., 2004). Segundo Toledo et al. (2007), os antibióticos agem no controle da microflora intestinal do animal, porém possibilitam o aparecimento de resistência bacteriana e também há indícios de aparecimento de resistência bacteriana por parte de bactérias patogênicas ao homem.

Os sucessivos relatos de problemas sanitários decorrentes da resistência microbiana a antibióticos, fez com que as autoridades sanitárias brasileiras instituíssem um comitê formado por representantes de entidades envolvidas com a alimentação animal e indústria de rações, criando o Plano Nacional de Controle de Resíduos Biológicos (PNCRB), o qual, através de portarias ministeriais, dita as normas pelas quais a indústria deverá adequar-se às exigências do mercado internacional (SEVERO, 2000; MILTENBURG, 2000). Em junho de 1999, a Comunidade Econômica Européia (CEE) baniu o uso de alguns antibióticos na alimentação de aves e em 2006, através da IN 65 publicada no DOU em 24/11/06, o Ministério da Agricultura e Abastecimento (MAPA) restringiu o uso de antibióticos como promotores de crescimento na alimentação de animais domésticos, com implicações para a indústria de carnes no Brasil (HALFHIDE, 2003).

Estudos realizados indicam que a simples retirada dos antibióticos promotores de crescimento da dieta de frangos de corte, leva a uma diminuição média no desempenho das aves de $3 \%$ a $7 \%$, além do impacto negativo sobre a saúde animal e aumento da mortalidade. Provavelmente a proibição total dos 
DELLA-FLORA, R.P., DIONELLO, N.J.L. e GERMANO, J.M. Utilização de mananoligossacarídeos como alternativa aos antibióticos na avicultura. PUBVET, Londrina, V. 6, N. 36, Ed. 223, Art. $1480,2012$.

antibióticos promotores de crescimento resultará em menor lucratividade para o setor (LANGHOUT, 2005).

Desse modo, de acordo com o mesmo autor, há necessidade de se introduzir estratégias novas, a fim de contornar tais efeitos. Uma abordagem nutricional amplamente utilizada é o uso de novos aditivos alimentares que são eficazes na melhoria do desempenho das aves, hipoteticamente através de modulação da microbiota no trato intestinal, como os prebióticos, que vêm sendo pesquisados e desenvolvidos (McINTOSH, 1996), dentre eles em especial o mananoligossacarídeos. Seu uso poderia eliminar problemas como resistência bacteriana e resíduos de antibióticos nos produtos avícolas, além de melhorar a imagem dos produtos avícolas perante o mercado consumidor (ALBINO et al., 2006).

Isso se baseia em novos conceitos de segurança alimentar e evidencia a necessidade de um melhor entendimento sobre a natureza, modo de ação dos reflexos do uso destes compostos sobre o desempenho animal.

\section{Prebióticos}

Prebióticos são ingredientes alimentares não-digestiveis que estimulam seletivamente o crescimento de bactérias endógenas como os Lactobacillus, Bifidobacterium, que beneficiam o hospedeiro (SOLIS DE LOS SANTOS et al., 2005).

Para uma substancia ser classificada com prebiótico, ela não pode ser hidrolisada ou absorvida na parte superior do trato gastrointestinal, e deve ser um substrato seletivo para bactérias comensais benéficas do cólon, afetando o crescimento ou o metabolismo, sendo capaz de alterar a microflora intestinal favorável e induzir a efeitos benéfico sintestinais ou sistêmicos, ao hospedeiro (DIONIZIO et al., 2002). De acordo com Silva e Nörnberg (2003) os efeitos 
DELLA-FLORA, R.P., DIONELLO, N.J.L. e GERMANO, J.M. Utilização de mananoligossacarídeos como alternativa aos antibióticos na avicultura. PUBVET, Londrina, V. 6, N. 36, Ed. 223, Art. 1480, 2012.

resultantes do uso dos prebióticos são evidenciados pelo crescimento das populações microbianas benéficas, pela melhora nas condições luminais, nas características anatômicas do trato gastrointestinal e no sistema imune e, em alguns casos, pela melhora no desempenho animal.

\section{Fontes de Prebióticos}

As principais fontes de prebióticos são alguns açucares absorvíveis ou não, fibras,peptídeos, proteínas, álcoois de açucares e os oligossacarídeos (DIONIZIO et al., 2002).Na nutrição animal, entre os prebióticos mais estudados como aditivos estão os frutoligossacarídeos, glucoligossacarídeos e os mananoligossacarídeos) (BUDIÑO et al.,2004).

\section{Oligossacarídeos}

Os oligossacarídeos são nomeados pelo açúcar predominante, e os suplementos mais comuns são os frutoligossacarídeos (FOS) e mananoligossacarídeos (MOS). Frutose e manana são acúcares reconhecidos pelos patógenos, mas são indisponíveis para uso quando estão ligados à forma de oligossacarídeo. Os patógenos são atraídos a se ligarem ao oligossacarídeo e então, tornam-se incapazes de aderirem à mucosa intestinal (McCann etial., 2006).

Autores têm sugerido que a suplementação com oligossacarídeos podem ter efeito prebiótico por aumentar a produção de ácido lático, induzindo, então a proliferação de bactérias benéficas e melhorando o sistema imune (SAVAGE et al., 1996). 
DELLA-FLORA, R.P., DIONELLO, N.J.L. e GERMANO, J.M. Utilização de mananoligossacarídeos como alternativa aos antibióticos na avicultura. PUBVET, Londrina, V. 6, N. 36, Ed. 223, Art. 1480, 2012.

\section{Mananoligossacarídeos}

Gibson e Roberfroid (1995) relataram que os mananoligossacarídeos são pequenos polímeros de manose encontrados em maior quantidade em componentes de células de leveduras. Leslie (1996) verificou que a microbiota benéfica pode utilizar os mananoligossacarídeos como fonte de energia, ao contrario da maioria dos patógenos. Os benefícios dos MOS são baseados em propriedades que incluem a modificação da flora intestinal, a redução na taxa de turnover da mucosa e a modulação do sistema imune no lúmen intestinal. Tratase de propriedades cujo potencial é de aumentar a taxa de crescimento, a eficiência de conversão alimentar e a viabilidade em criação de frangos e perus (SHANE, 2001).

O outro componente da parede celular da levedura, D-manana, também demonstrou atividade antioxidante e antimutagênica (KRIZKOVÁ et al., 2001). Lectinas específicas de manose predominam em muitas bactérias patogênicas intestinais e, por ligações na superfície do epitélio do intestino, conferem aderência e subseqüente colonização e infecção (BAUMLER et al., 1997). As _-Dmananas se ligam aos receptores tipo lecitinas específicos de manose das bactérias enteropatogênicas como E.coli e Salmonella spp. e, neste caso, servem como atrativos e previnem a adesão às glicoproteínas da superfície do vilo e subseqüente colonização e disseminação dos patógenos bacterianos (FIRON et al., 1983).

No trato gastrintestinal, as lectinas presentes nas fimbrias tipo I das bactérias patogênicas se ligam a carboidratos encontrados na parede intestinal. Este processo é crítico para que se inicie uma colonização bacteriana, com subseqüente patogênese. Este reconhecimento do patógeno é dependente do reconhecimento de oligômeros de manose de cadeia curta e de glicoconjugados de manose de cadeia curta que se exteriorizam a partir da superfície epitelial. 
DELLA-FLORA, R.P., DIONELLO, N.J.L. e GERMANO, J.M. Utilização de mananoligossacarídeos como alternativa aos antibióticos na avicultura. PUBVET, Londrina, V. 6, N. 36, Ed. 223, Art. 1480, 2012.

Várias pesquisas indicam que é possível bloquear o sítio de ligação do patógeno com o sitio receptor do patógeno a nível epitelial ao oferecer oligossacarídeos (polimanoses) na dieta dos animais (OYOTO et al., 1989). Assim, os oligossacarídeos servem como a primeira linha de proteção ao bloquear a colonização.

Vale assinalar que as alternativas aos antibióticos devem ser capazes de alterar $\mathrm{o} \mathrm{pH}$ intestinal, manter as mucinas protetoras do intestino, selecionar organismos benéficos ou atuar contra patógenos. Além disso, devem aumentar tanto a fermentação ácida quanto a absorção de nutrientes e a resposta imune humoral (FERKET, 2004).

Provavelmente um dos papeis mais importantes dos mananoligossacarídeos está na sua capacidade de modificar a morfologia e a estrutura da parede intestinal. Trata-se de um efeito na ecologia microbiana gastrointestinal. As glicomananas, em condições de pH do aparelho digestivo, são capazes de se ligar seletivamente e inativar as micotoxinas no lúmen intestinal. Estas propriedades têm grande potencial para melhorar o desempenho e diminuir a mortalidade de frangos de corte e perus. (SHANE, 2001).

Estudos conduzidos na Universidade Estadual de Oregon demonstraram uma redução na profundidade da cripta de perus recebendo mananoligossacarideos durante 8 semanas (SAVAGE et al., 1997). Estas alterações foram diretamente correlacionadas com o crescimento dos animais.

Outros estudos demonstraram que a inclusão de parede celular de leveduras na dieta de frangos resulta em aumento do tamanho da vilosidade durante os primeiros 7 dias de vida, propiciando aumento do peso corporal durante todo o período de produção (SANTIN et al., 2001).

Iji(2003) avaliaram a resposta da célula intestinal ao mananoligossacarídio em aves recebendo dieta a base de sorgo. A suplementação de mananoligossacarídios resultou em maior desenvolvimento da vilosidade do 
DELLA-FLORA, R.P., DIONELLO, N.J.L. e GERMANO, J.M. Utilização de mananoligossacarídeos como alternativa aos antibióticos na avicultura. PUBVET, Londrina, V. 6, N. 36, Ed. 223, Art. 1480, 2012.

jejuno. O conteúdo de RNA da mucosa ileal foi significativamente maior em pintos recebendo mananoligossacarídeos. Entretanto, isto não foi traduzido em crescimento da mucosa ou em diferenças na atividade enzimática da mucosa do íleo. A inclusão de mananoligossacarídios propiciou maior atividade da maltase $(P<0.01)$, leucina aminopeptidase $(P<0.05)$ e fosfatase alcalina $(P<0.001)$ no jejuno.

Uni e Smirov (2006) investigaram a possibilidade de adição de mananoligossacaridios sobre a biosíntese de mucina e secreção no intestino delgado. Os resultados indicaram que os mananoligossacarideos apresentam um efeito estimulador da mucina. O mananoligossacarideo propiciou aumento no desenvolvimento das células caliciformes, que produzem mucina, resultando em maior camada de muco. Interessante é que a inclusão de mananoligossacarideo na dieta aumentou a expressão do mRNA do gene MUC 2. Os autores concluiram que os mananoligossacarídios interagem com as lectinas presentes na membrane celular, o que regula o crescimento celular e a sobrevivência ao interagir com proteinas nucleares e do citoplasma, afetando o sistema de comunicação intracelular.

Estes estudos sugerem que os mananoligossacarideos podem melhorar a eficiência do crescimento através de mecanismos que alteram a estrutura e a atividade funcional dos tecidos. Possivelmente este seja um novo papel dos carboidratos funcionais e que venham a contribuir para a melhora no desempenho dos mesmos.

Macari \& Maiorka (2000) também verificaram maior ganho de peso em frango suplementados com $0,2 \%$ de MOS quando comparados aqueles que receberam o tratamento controle. Porém, estes resultados não se estenderam às respectivas conversões alimentares. 
DELLA-FLORA, R.P., DIONELLO, N.J.L. e GERMANO, J.M. Utilização de mananoligossacarídeos como alternativa aos antibióticos na avicultura. PUBVET, Londrina, V. 6, N. 36, Ed. 223, Art. $1480,2012$.

Stanley et al. (1996) observaram maior conteúdo em músculo e menores níveis de colesterol e gordura no peito e fígado, respectivamente, quando fornecido 0,05\% de MOS (Bio-MOS) em dietas para frangos de corte.

Spring et al. (2000) submeteram frangos de corte ao desafio com dois tipos de Salmonela e encontraram menores concentrações destas bactérias no trato intestinal de aves suplementadas com MOS em relação ao tratamento controle.

Macdonald (1995), citado por Swick (1996), em experimento com frangos de corte, observou melhora significativa da conversão alimentar e redução da mortalidade de animais alimentados com MOS. Em trabalho realizado com perus, Parks et al. (2001) observaram aumento no ganho de peso (na 20a semana de vida) e melhora na conversão alimentar(de 0 a 3 semanas e de 15 a 18 semanas de idade) dos animais que receberam MOS em relação ao tratamento controle.

Os autores concluíram que o MOS pode ser utilizado como alternativa aos antibióticos.

\section{CONCLUSÃO}

O MOS são compostos biologicamente seguros à saúde humana e animal, justificando o seu uso alternativo em substituição a certas drogas veterinárias usadas na prevenção de alterações do trato gastrintestinal e/ou como promotoras do crescimento. Entretanto, as respostas biológicas na nutrição animal nem sempre são evidenciadas, o que pode estar relacionado com a composição química dos demais ingredientes da dieta, com a dosagem adicionada, com a adaptação e a seletividade da microbiota ao MOS, ou com o nível de estresse do animal. Assim, mais estudos se fazem necessários para esclarecer as condições nas quais há necessidade real de sua suplementação. 
DELLA-FLORA, R.P., DIONELLO, N.J.L. e GERMANO, J.M. Utilização de mananoligossacarídeos como alternativa aos antibióticos na avicultura. PUBVET, Londrina, V. 6, N. 36, Ed. 223, Art. $1480,2012$.

\section{REVISÃO BIBLIOGRÁFICA}

ALBINO, L.F.T.; FERES, F.A.; DIONÍZIO, M.A.; ROSTAGNO, H.S.; VARGAS, JR, J.G.; CARVALHO, D.C.O.; GOMES, P.C.; COSTA, C.H.R. Uso de prebióticos a base de mananoligossacarídeo em rações para frangos de corte. Revista Brasileira de Zootecnia, v.35, n.3, p.742-749, 2006 .

BAUMLER, A.J.; TSOLIS, R.M.; HEFFRON, F. Fimbrial adhesions of Salmonella typhimurium. Role in bacterial interactions with epithelial cells. Advances in Experimental Medicine and Biology. v.412, p.149-158, 1997.

BUDIÑO, F. E. L.; THOMAZ, M. C.; KRONKA, R. N.; JÚNIOR, J. M. P.; SANTANA, A. E., TUCCI, F. M.; FRAGA, A. L.; SCANDOLERA, A. J.; HUAYNATE, R. A. R. Influência da adição de probiótico e/ou prebiótico em dietas de leitões desmamados sobre as atividades das enzimas digestivas e parâmetros sangüineos. Acta Scientiarum. Animal Sciences, Maringá, v. 26, p. 529-536, 2004.

DIONIZIO, M. A.; BERTECHINI, A. G.; KATO, R. K.; TEIXEIRA, A. S. Prebióticos como promotores de crescimento para frangos de corte - desempenho e rendimento de carcaça. Ciência Agrotécnica, Lavras, Edição Especial, p. 1580-1587, 2002.

FERKET, P. R. Alternatives to antibiotics in poultry production: responses, practical experience and recommendations. In: INTERNATIONAL FEED INDUSTRY SYMPOSIUM, 20, 2004, Lexington. Proceedings... Lexington: Alltech, 2004. p. 54-67.

FIRON, N.; OFEK, I.; SHARON, N. Carbohydrate specificity of the surface lectins of Escherichia coli, Klebsiella pneumoniae, and Salmonella typhimurium. Carbohydrate Research. v.120, p.235-249, 1983

FRANCO, L. G. Medidas adotadas na Nutrição Animal visando à saúde intestinal. 2010. Nutrition for Tomorrow. Disponível em: http://www.nftalliance.com.br/. Acessado em: 17/07/2012

GIBSON, G. R.; BEATTY, E. R.; WANG, X.; CUMMINGS, J. H. Selective stimulation of bifidobacteria in the human colon by oligofructose and inulin. Gastroenterology, v. 108, n. 4, p. 975-982, 1995.

GIBSON, G. R.; ROBERFROID, M. B. Dietary modulation of the human colonic microbiota: introducing the concept of prebiotics. Journal of Nutrition, Bethesda, v. 125,p. 401-412, 1995.

HALFHIDE, B. Role of probiotics in animal nutrition and their link to the demands of European consumers. In: ROLE OF THE EUROPEAN PROBIOTIC ASOCIATION. Proceedings... Needertlands, p. $3-4,2003$.

IJI, P. A.; SAKI, A. A.; TIVEY, D. R. Intestinal development and body growth of broiler chicks on diets supplemented with non-starch polysaccharides. Animal Feed Science and Technology, $v$. 89, n. 1 , p. $175-188,2003$

KRIŽKOVÁ, L.; _URA_KOVÁ, Z.; ŠANDULA, J.; SASINKOVÁ, V.; KRAJ_OVI_, J. Antioxidative and antimutagenic activity of yeast cell wall mannans in vitro. Mutation Research. v.497, p.213222, 2001. 
LANGHOUT, P. A visão da indústria e recentes avanços. In: Conferência APINCO 2005, Santos, SP. Anais... Conferência APINCO 2005 de Ciência e Tecnologia Avícola, Santos, p. 21-33, 2005.

LESLIE, A. J. The ever-increasing role of biotechnology in the poultry industry: lessons from the past and thoughts for the future. North American University Tour, 1996, p. 65-85.

MACARI, M.; MAIORKA, A. Função gastrintestinal e seu impacto no rendimento avícola. In: CONFERÊNCIA APINCO.2000 DE CIÊNCIA E TECNOLOGIA AVÍCOLAS, 2000, Campinas. Anais... Campinas : FACTA, 2000. V.2. p.161-174

MACHADO, A.M.B.; DIAS, E.S.; SANTOS, É.C.S.; FREITAS, R.T.F. Composto exaurido do cogumelo Agaricus blazei na dieta de frangos de corte. Revista Brasileira de Zootecnia, v.36, n.4, 2007.

MAPA - Instrução Normativa no 65/2006 de 24/11/2006 publicada no em DOU 24.11.2006, em www.agricultura.gov.br acessos em 18.01.2009..

MATEOS, G. G.; GONZÁLES-ALVARADO, J. M.; LÁZARO, R. Facing the realities of poultry health and performance without antibiotics in Europe. In: INTERNATIONAL FEED INDUSTRY SYMPOSIUM, 20., 2004, Lexington. Proceedings... Lexington: Alltech, 2004. p. 69-79.

MATHEW, A.G. et al. Effect of galactan on selected microbial populations and $\mathrm{pH}$ and volatile fatty acids in the ileum of the weanling pig. J Anim Sci, Savoy, v.71, n.6, p.1503-1509,1993.

MCCANN, M.E.E.; NEWELL, E.; PRESTON, C.; FORBES, K. The use of mannanoligosaccharides and/or tannin in broiler diets. International Journal of Poultry Science.v.5, n.9, p.873-879, 2006.

McINTOSH, G.H. Probiotics and colon cancer prevention. Asia Pacif J Clin Nutr, Oxfordshire, v.5, n.1, p.48-52, 1996

MILTEMBURG, G. Promotores e aditivos de crescimento em Avicultura. In: CONFERENCIA APINCO DE CIÊNCIA E TECNOLOGIA AVICOLAS, 2000, Campinas. Anais... Campinas: FACTA, 2000. p. 204-215.

OYOFO, B.A., DELOACH, J.R., CORRIER, D.E., NORMAN, J.O., ZIPRIN, R.L., and MOLLENHAUER, H.H. (1989). Effect of carbohydrates on Salmonella typhimurium colonization in broiler chickens. Avian Diseases 33(3): p. 531-534

PARKS, C.W.; GRIMES, J.L.; FERKET, P.R. et al. The effect of mannanoligosaccharides, bambermycins, and virginiamycin on performance of large white male market turkeys. Poultry Science, v.80, n.6, p.718-723, 2001.

PELICANO, E.R.L.; SOUZA, P.A; SOUZA, H.B.A. et al. Utilização de probiótico e/ ou prebiótico como promotores de crescimento em rações iniciais de frango de corte. Revista Brasileira de Ciência Avícola, Suplemento 6, p.17, 2004.

ROY, M.; GIBSON, G.R. Probiotics and prebiotics .microbal in menu. 1999. Capturado em 21 de agosto de 2012.Online. Disponível na internet http:// www.babelfish.altavista.com/cgi-bm. 
SALYERS, A.A. Agricultural use of antibiotics and antibioticresistance in human pathogens: is there a link? In: ALLTECH.SANNUAL SYMPOSIUM, 15., 1999, Nottingham. Proceedings... Nottingham : Alltech, 1999. p.155.171.

SANTIN, E., MAIORKA, A., MACARI, M., GRECCO, M., SANCHEZ, J.C., OKADA, T.M., and MYASAKA, A.M. Performance and intestinal mucosa development of broiler chickens fed diets containing Saccharomyces cerevisiae cell wall. Journal of Applied Poultry Research 10(3): p. 236$244,2001$.

SAVAGE, T.F.; COTTER, P.F.; ZAKRZEWSKA, E.I. The effects of feeding mannan oligosaccharide on immunoglobulins, plasma IgG and bile IgA, of wrolstad MW male turkeys. Poultry Science, v.75, supp.1, p.143, 1996.

SAVAGE, T.F., ZAKRZEWSKA, E.I., and ANDREASEN, J.R. The effects of feeding mannan oligosaccharide supplemented diets to poults on performance and the morphology of the small intestine. Poultry Science 76(Suppl 1): p. 139, 1997.

SEVERO, M. P. F. Plano de controle de resíduos em produtos de origem animal no Brasil: Ministério da Agricultura e Abastecimento. In: CONFERENCIA APINCO DE CIÊNCIA E TECNOLOGIA AVICOLAS, 2000, Campinas. Anais... Campinas: FACTA, 2000. p. 242-251

SHANE, S. M. Mannan oligosaccharides in poultry nutrition: mechanisms and benefits. In: INTERNATIONAL FEED INDUSTRY SYMPOSIUM, 17 Lexington. Proceedings...Lexington: Alltech, 2001. p. $65-77,2001$.

SILVA DA, L. P.; NÖRNBERG, J. L. Prebióticos na nutrição de não ruminantes. Ciência Rural, Santa Maria, v. 33, p. 983-990, 2003.

SOLIS DE LOS SANTOS, F.; FARNELL, M.B.; TÉLLEZ, G.; BALOG, J.M.; ANTHONY, N.B.; TORRESRODRIGUEZ, A.; HIGGINS, S.; HARGIS, B.M.; DONOGHUE, A.M. Effect of prebiotic on gut development and ascites incidence of broilers reared in a hypoxic environment. Poultry Science. v.84, n.7, 2005.

SPRING, P.; WENK, C.; DAWSON, K.A. et al. The effects of dietary mannaoligosaccharides on cecal parameters and the concentrations of enteric bacteria in the ceca of salmonellachallenged broiler chicks. Poultry Science, v.79, n.2, p.205- 211, 2000.

STANLEY, V.G.; GRAY, C.; CHUKWU, H. Effects of mannan oligosaccharide (Bio-MOS) on liver and egg cholesterol and tissue protein concentration in chickens. Poultry Sci, Champaign, v.75, supp.1, p.61, 1996

SWICK, R.A. Role of growth promotants in poultry and swine feed. 1996. Acesso em: 09/08/2012. Online. Disponível em: http://www.asasea.com/technical/an04-1996.html.

TOLEDO, G.S.P.; COSTA, P.T.C.; SILVA, L.P.; PINTO, D.; PRISCILA, F.; POLETTO, C.J. Desempenho de frangos de corte alimentados com dietas contendo antibiótico e/ou fitoterápico como promotores, adicionados isoladamente ou associados. Ciência Rural, v.37, n.6, 2007.

UNI,Z. and SMIRNOV, A.Modulating mucin dynamics using functional carbohydrates. Gut microbiology: research to improve health, immune response and nutrition. Fifth RRI-INRA Joint Symposium 21-23 June, Aberdeen, UK.2006. 